\title{
ESTUDIO ICONOGRÁFICO DEL MENOLOGIO EN SAN PEDRO DE TREVIÑO
}

Gorka López de Munain Iturrospe

Universidad del País Vasco

RESUMEN: La sexta arquivolta de la portada treviñesa ha concitado últimamente a numerosos estudiosos de la Historia del Arte tanto por su singularidad plástica como por su difícil interpretación. El ciclo de los meses y los signos zodiacales que recorren las dovelas está incompleto lo que ha dado lugar a numerosos comentarios en variadas direcciones. Con este trabajo trataremos de aportar nuevas luces ahondando especialmente en la iconografía de las figuras y sus precedentes para así poder establecer una explicación lo más coherente posible.

Palabras clave: Menologio, iconografía, meses, Treviño, calendario.

ABSTRACT: The sixth archivolt of the church of Treviño has been the subject of many studies because of its singular iconography and its difficult interpretation. Along the archivolt appears the cycle of the labors of the month and zodiacal signs but it isn't complete. In consequence, many studious tried to explain the portal in several directions. With this work we would try to bring new facts studying the iconography of the figures and their precedents in order to explain the whole portal in a coherent way.

Keywords: The labors (occupations) of the months, iconography, Treviño, calendar. 


\section{Estado de la cuestión}

En el año 1161, de acuerdo con la política de villazgo emprendida por el rey Sancho VI de Navarra en su reino, se concede el fuero a Treviño con la intención de potenciar las zonas fronterizas. En 1200 Treviño pasa a formar parte de la corona de Castilla y pocos años después, Alfonso X confirmará las costumbres y franquicias de la villa otorgando nuevo fuero en $1254^{1}$. Es en estos años cuando la villa comienza a tener su verdadero apogeo y parece ser que entonces se inicia la construcción de la fábrica gótica a la que nos referiremos en el presente trabajo. Esta iglesia fue parcialmente reconstruida entre los siglos XVII y XVIII y de la antigua obra medieval (s. XIII-XIV), son pocos los restos que hoy en día se conservan. Entre ellos cabe destacar la portada dispuesta en el lado meridional, junto con una escultura en piedra de la Virgen Blanca ubicada en el ángulo sur-este. A su vez se observa en el muro norte el perfil degradado de una antigua portada de tamaño considerable $y$, en el hastial, otra de menor tamaño, ambas de estilo gótico.

En la sexta arquivolta de la portada, la única que se encuentra decorada con motivos figurativos, nos encontramos representadas en toda su extensión las escenas alusivas a cada mes acompañadas de su signo zodiacal correspondiente. Los primeros en advertir la temática que allí se encontraba esculpida fueron Micaela Portilla y J. Eguía López en el Catálogo Monumental de la Diócesis de Vitoria en 1968². Quince años después Felicitas Martínez de Salinas $^{3}$ realizó el primer estudio iconográfico del mensario treviñés, tomando como referente el magnífico estudio de Antonio Herrera Casado sobre el calendario de Beleña de Sorbe ${ }^{4}$. En 1992 Margarita Ruiz Maldonado 5 publicó un artículo sobre la portada centrándose principalmente en algunos aspectos singulares, que los trabajos precedentes habían obviado, como la supuesta Anunciación situada en lugar de los meses de junio y julio. Sin embargo otros aspectos quedaban aún oscuros, es el caso de la presencia de sólo ocho signos zodiacales y también de las diez representaciones mensuales por lo que tan

1. Portilla, Micaela J., Por Álava a Compostela, Álava Monumentos en su historia, Diputación Foral de Álava, Vitoria, 1991. p. 12-13.

2. Portilla, M.J. y Eguía López, J., Catálogo Monumental. Diócesis de Vitoria II, Arciprestazgo de Treviño, Albaina y Campezo, Vitoria, 1968, pp. 207-220.

3. Martínez de Salinas Ocio, Felicitas, "Portada de la parroquia de San Pedro de Treviño", Sociedad de Estudios Vascos, Cuadernos de Sección Artes Plásticas y Monumentales, II, 1983, p.19.

4. Herrera Casado, Antonio, "El calendario románico de Beleña de Sorbe (Guadalajara)", Traza y Baza, Cuadernos Hispanos de simbología, arte y literartura, V, Universidad de Barcelona, 1974, pp. 31-41.

5. Ruiz Maldonado, Margarita, "Precisiones acerca del Calendario de Treviño", Boletín del Museo e Instituto "Camón Aznar", XLVII, 1992, pp. 5-13. 
sólo un año después, Isabel Frontón Simón ${ }^{6}$, publicó un extenso trabajo sobre la portada dedicando especial atención a las imágenes zodiacales. Los exhaustivos trabajos realizados por Castiñeiras González $z^{7}$ sobre los menologios medievales suponen un punto de inflexión en el estudio de esta temática. En el libro dedicado a los calendarios hispanos ${ }^{8}$, el autor menciona el repertorio burgalés sin llegar a realizar un estudio pormenorizado, pero en cambio sí aporta unas precisiones iconográficas de gran interés además de apuntar un posible precedente francés en la iglesia de Mimizan.

Siendo notable la dedicación que ha tenido la obra de Treviño por parte de los diferentes especialistas, ninguno de ellos ha conseguido desentrañar definitivamente la singular iconografía que en la mencionada arquivolta se despliega. Son numerosos los datos que no concuerdan y que nos hacen sospechar sobre la unidad original de esta arquivolta. Si la comparamos con otros ciclos conservados más o menos coetáneos, en casi todos los casos se mantienen completos, tanto los mensuales, como los combinados con los signos del zodíaco, si bien estos últimos son mucho más escasos. En Treviño son 22 (y no 24) las dovelas que componen la sexta arquivolta, problema al que nos tendremos que enfrentar ya que la portada en su conjunto parece mantener una unidad y coherencia arquitectónica en relación al pórtico que la cubre. Esto en principio nos invita a considerar que todo el conjunto portada-pórtico debió construirse a la vez y nada parece indicar una alteración posterior salvo las incongruencias iconográficas del repertorio esculpido. Otra incoherencia la vemos en la supuesta Anunciación que aparece intercalada, tema en principio totalmente ajeno a los menologios medievales pues no existen precedentes documentados, y que además nos muestra un trabajo escultórico claramente diferenciado de las restantes piezas.

A lo largo de las próximas líneas realizaremos un estudio iconográfico individualizado para cada una de las figuras del repertorio mensual. Con él trataremos de poner luz a alguna de las incógnitas que han hecho de esta portada una obra de gran interés para los historiadores del arte. Pero antes, conviene ahondar en la cronología de la portada para poder afinar cuanto nos sea posible el posterior estudio de las dovelas.

6. Frontón Simón, Isabel, "El calendario medieval de San Pedro de Treviño (Burgos)", Boletín del Museo e Instituto "Camón Aznar", LII, 1993, pp.169-188.

7. Castiñeiras González, M. A., "Las fuentes antiguas en el monologio medieval hispano: la pervivencia literaria e iconográfica de la Etimologías de Isidoro y el calendario de Filócalo". Boletín del Museo Arqueológico Nacional, XII, 1994, pp. 77-100; El Calendario Medieval Hispano Textos e imágenes (siglos XIV-XIV). Junta de Castilla y León Consejería de Educación y Cultura, 1996.

8. Castiñeiras, M. A., El calendario medieval... pp. 105-106. 


\section{En torno a la cronología de la portada}

Desgraciadamente, para valorar una aproximación cronológica de la portada, sólo podemos contar con el recurso débil de la hipótesis a falta de documentos sólidos. Es sabido que las obras de las catedrales, por la enorme complejidad de su construcción, podían durar muchos años, en cambio las de un castillo se hacían con gran celeridad por motivos obvios. En este caso estamos ante una iglesia parroquial que obedece a intereses y condiciones diferentes. La mayor parte de los recursos tanto económicos como humanos se destinaban a la construcción del presbiterio y a partir de ahí los trabajos se ralentizaban una vez que la iglesia quedaba consagrada9. San Pedro de Treviño debió iniciarse a partir de 1254 cuando la villa obtiene la carta foral del rey castellano, aunque no se tiene constancia documental de tal suceso. Estilísticamente las piezas medievales que han llegado (tales como la pila bautismal o la portada misma $^{10}$ ) hasta nuestros días nos ofrecen una datación que en principio se ajusta a lo presupuesto: la segunda mitad del siglo XIII. Sin embargo, también encontramos elementos como la talla de la Virgen Blanca que Lucía Lahoz sitúa en torno a 1300, lo que nos advierte sobre una posible ampliación del abanico cronológico"1 ${ }^{11}$.

La portada ofrece un trabajo escultórico y una iconografía propia de los tiempos góticos ${ }^{12}$. A lo largo de las arquivoltas se despliega todo un canto a la naturaleza y su relación con el hombre y las bestias que habitan el mundo.

9. Graciani, Amparo, (Ed.), La técnica de la arquitectura medieval, "la economía de la construcción en la Edad Media" por José Antonio Solís Burgos, p. 147.

10. Portilla, M. J., Catálogo... op.cit. pp. 211-213.

11. Lahoz, Lucía, El arte Gótico en Álava, Diputación Foral de Álava, Vitoria, 1999, p. 47.

12. La iconografía de las obras nos aporta otra perspectiva que puede ayudarnos a ajustar mejor las fechas. Anticipándonos al análisis de las dovelas que detallaremos a continuación, salta a la vista la similitud de la obra treviñesa con obras de fechas tardías como el calendario de San Marcos de Venecia o las claves del claustro de la Catedral de Pamplona. Esta obra se construyó en varias etapas. En la primera, se levantaron las galerías este y norte, así como la capilla Barbazana en unas fechas que van de 1280 a 1318. Es precisamente en este tramo (norte) donde se encuentra parte del calendario esculpido que nos interesa para este estudio Cfr. VV.AA., La Catedral de Pamplona, CAN, 1994, Tomo I, p. 171; Idem, p. 198. No parece pues tan descabellado pensar que los artistas que trabajaron en Treviño, manejaran los mismos modelos con los que contaron sus compañeros en la capital del reino navarro, ya que las fechas pueden llegar a solaparse si consideramos un retraso prudente de unos 30 años desde el inicio de las obras hasta la ejecución de la portada. Podemos por tanto señalar que para ambas obras se contó con material muy similar, tal vez códices miniados, libros de modelos como el de Villard de Honnecourt o algún otro medio perecedero que no ha llegado hasta nuestros días. Quién sabe si el taller que trabajó en Treviño, acaso tuvo que abandonar las obras para atender un encargo de mucho mayor rango como es la participación en la construcción de un claustro catedralicio, y la obra treviñesa tuvo que cerrarse de urgencia sin poder completarse el programa iconográfico. 
Aparecen follajes con diferentes tipos de plantas entre las que emergen cabezas humanas, representado los diferentes estamentos sociales de la época. También se muestran figuras de aspecto negroide que no hace más que incidir en la variedad de la naturaleza representada en la que existe tanto el bien como el mal. En el arranque de cada una de las arquivoltas unos ángeles actúan de basamento simbólico sobre el que crece el mundo terrenal expresado con los trabajos de los meses.

A su vez se trata de una obra en la que la numerología sacra tiene una fuerte presencia de nuevo en estrecha vinculación con la naturaleza. Se despliegan en sentido abocinado seis grandes columnas a cada lado de las jambas, cuya suma hace doce, el número de meses y signos zodiacales. Entre estas columnas, aparecen de forma vertical de nuevo doce flores esquemáticas que nos muestran su evolución a lo largo del año (apertura, floración, cierre).

\section{Estudio iconográfico}

\subsection{La iconografía de los meses}

La iconografía de los meses es un tema de larga tradición, teniendo sus orígenes en la antigua cultura grecolatina. Son escasos los ejemplos de calendarios ilustrados que han llegado hasta nuestros días de esta época, pero menos aún los que combinan los signos zodiacales con los ciclos men-

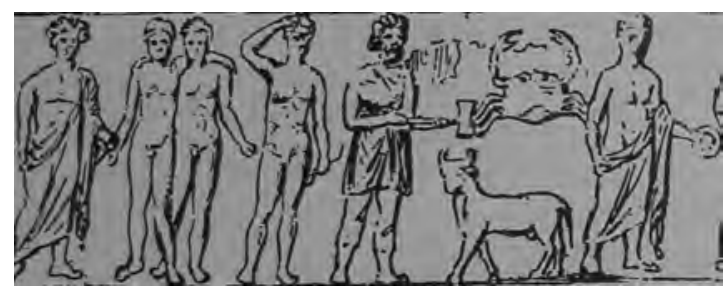

Figura 1: Detalle friso géminis y cáncer. Hagios Eleutherios. Atenas. (Webster). suales. El friso helenístico (S II-I a.c.) que se encuentra recolocado en la fachada de la iglesia de Hagios Eleutherios de Atenas es uno de los ejemplos más tempranos. A grandes rasgos el carácter general del friso es el siguiente: en cada una de las secciones se narran unas escenas cuyos personajes representan las ideas propias que los griegos tenían para cada mes, así como las festividades y rituales religiosos más relevantes, acompañadas de los signos zodiacales correspondien-

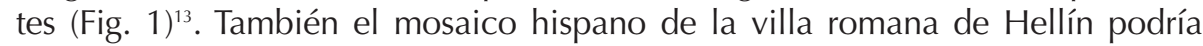
considerarse en parte dentro de esta tipología pues combina figuras divinas con figuras alusivas a los signos zodiacales conformando en conjunto las alegorías de

13. Webster, James Carson, The Labors of the months in Antique and medieval art, to the end of the twelfth century, Princeton University Press, Princeton, 1938, p. 12. 
los meses ${ }^{14}$. Aunque es muy difícil trazar una relación iconográfica entre estos calendarios y los surgidos en el Medioevo, hemos de considerarlos como el primero de los eslabones de una cadena que no se corta a lo largo de los siglos, pero que sí evoluciona adaptándose a su época.

En cuanto a las representaciones de la antigüedad, en su mayoría son de tipo alegórico o personificaciones (Calendario de Filócalo $\left.{ }^{15}\right)$, pero también se observan unas incipientes manifestaciones activas, casi siempre en clara vinculación con temas agrícolas (mosaico de Cartago, Sarcófago Juno Basso (laterales), puerta de Marte de Reims). Estas poco a poco irán imponiéndose en siglos posteriores hasta terminar por afincarse como el tipo iconográfico

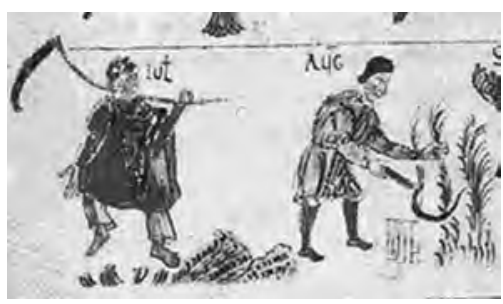

Figura 2: Detalle julio y agosto, ms 387, folio 90r., Abadía de San Pedro, Salzburgo. definitivo en la Edad Media. El punto de inflexión lo marcará la aparición de las carmina Salzburgiana (siglo IX) y los manuscritos de la escuela de iluminación de Salzburgo, obras literarias y gráficas que asentarán el giro decisivo hacia las escenas activas (Fig. 2) en las que aparecen desarrolladas las actividades propias de cada mes ${ }^{16}$. Así pues, para el estudio del calendario treviñés repararemos en las obras artísticas posteriores al siglo IX.

En el ámbito hispano, el gran desarrollo en formato monumental se produjo a principios del siglo XII, fecha singularmente temprana para el mundo occidental que sin embargo no consiguió cuajar en una tradición sólida y coherente ${ }^{17}$. Es por ello que a la hora de trazar precedentes consideraremos con mayor incidencia los repertorios franceses e italianos que penetraron en la península, muy probablemente a través de las vías de peregrinación.

14. Sogorb Álvarez, $M^{a}$ del Carmen, "Los mosaicos de la villa romana de Hellín", Boletín del Museo Arqueológico Nacional, Tomo V no 1 y 2, 1987, pp. 21-42.

15. El calendario de Filócalo o Cronografo del 354 es un calendario romano que aparece en el año 354, realizado por el calígrafo y gravador Furius Dionysius Filocalus, dividido en dos grandes partes. Las imágenes de los meses aparecen acompañando los Fastos de la primera parte. Hoy en día sólo conocemos las copias que se realizaron en época renacentista de una versión carolingia. Para conocer en profundidad los diferentes aspectos de este calendario, la obra de referencia sigue siendo Le Calendrier De 354, étude sur son texte et ses illustrations, de Henri Stern, editada en París en 1953.

16. Webster, J. C., The Labors of the months... p.37.

17. Sin embargo, los ciclos peninsulares tienen características propias como la colocación de la matanza en noviembre por San Martín y el banquete en Diciembre, Castiñeiras, El calendario medieval... p.65. 


\subsection{El menologio de San Pedro de Treviño}

A continuación, y considerando todo lo anteriormente dicho, pasaremos a analizar una por una las dovelas referidas a los meses que conforman la portada. Son muchos los problemas que se plantean para su estudio y abordarlos de manera general resultaría muy confuso. Es por ello que hemos optado por dividir las dovelas entre "no identificadas" e "identificadas" y de esta manera en cada caso se realizarán las aclaraciones pertinentes.

Por algún motivo que se nos escapa hoy día, esta portada no fue concluida con su programa completo. Los arranques de cada uno de los lados se hacen correctamente, manteniendo la iconografía de cada dovela de manera coherente. Sin embargo mientras los canteros fueron colocando las dovelas sobre el cimbrado, algún problema debió ocurrir que motivó se concluyera de manera incompleta. No obstante debemos rechazar que se intercalaran dovelas de otra construcción ya que todas ellas tienen el característico basamento para cada figura, incluidas las "no identificadas". Sospechamos que las obras fueron concluidas por algún cantero diferente que desconocía la iconografía representada y tuvo que ingeniárselas para poder cerrar la obra.

\subsubsection{Dovelas "identificadas"}

Conviene señalar que estas dovelas mantienen una unidad estilística aceptable aún cuando el deterioro de alguna de ellas complica sensiblemente esta apreciación. El taller que trabajó en Treviño destaca con una calidad muy por encima de las obras que le rodean como la portada de Peñacerrada, de carácter mucho más rural. Sin embargo en este taller podemos apreciar más de una mano. En el basamento de la Virgen Blanca, que flanquea el ángulo sur-este de la parroquia, observamos una escena de vendimia en la que unos labradores se afanan en cortar los racimos que salen de las orejas de dos grandes rostros. La inclinación de las cabezas de los vendimiadores, el juego de piernas y brazos, y un canon sensiblemente alargado, dota a las figuras de una gracia que junto con el detallismo de los racimos y los pámpanos, hace de esta peana una obra de notable calidad. Por el tema abordado, no parece arriesgado asegurar que esta pieza se elaboró por el mismo taller que realizara la portada.

Sin embargo en las dovelas del portal la calidad estilística se ve mermada. Las manos de las figuras están absolutamente inanimadas (Jano), el canon es más achaparrado (Marzo) y los pliegues resultan algo toscos. Los rostros, en algunos casos, como el anciano que se calienta los pies en la dovela de febrero o el rey de primavera, muestran una calidad semejante a la de la peana antes señalada, lo que nos habla de un trabajo conjunto entre los artistas más destacados y los de segunda fila, probablemente locales. Las dificultades nos 
asaltan al analizar las figuras "no identificadas" en las que apreciamos una calidad muy inferior (géminis, profeta, anunciación), probablemente ejecutadas completamente por artistas locales, sin la asistencia de los más aventajados.

\section{Enero- Jano:}

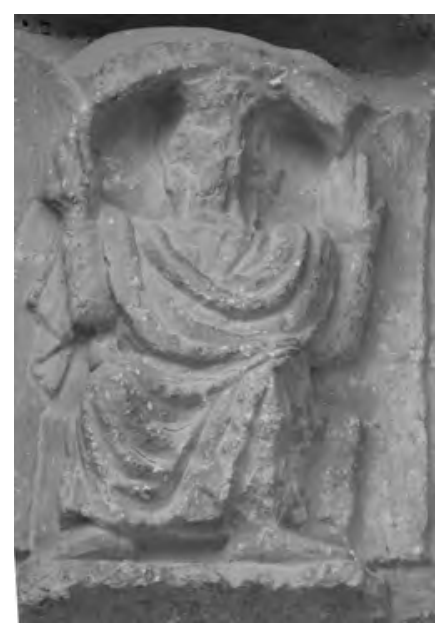

Figura 3: Detalle enero.

En la primera dovela nos encontramos la figura del dios bicéfalo Jano (Fig. 3), una de las numerosas imágenes de la antigüedad que ha pervivido en los tiempos del Medioevo. Para comprender su significado, debemos remontarnos a Numa Pompilius (s. VIII-VII a.C.), quien solucionó los desfases temporales del antiguo calendario griego incluyendo los meses de enero y febrero. Al mes de enero lo llamó lanus en honor al primer rey de Lacio, representante de la paz y de todos los inicios ${ }^{18}$. El etrusco Tarquinio Priscio, aproximadamente en el año 153 a.c., realizó un nuevo intento de perfeccionamiento del calendario adaptándolo esta vez a los ciclos solares para evitar así los desajustes estacionales sufridos hasta el momento. La solución fue establecer un decimotercer mes conocido como Marcedoinus (según Plutarco) o Mensis intercalaris de 22 a 23 días, que se incluía ciertos años por decisión del Pontificex Maximus para equilibrar los desfases. Este nuevo sistema se conoce como el calendario Republicano o prejuliano y es entre este momento y la creación del calendario juliano cuando enero pasó a ser definitivamente el primer mes del año ${ }^{19}$. La entrada de esta imagen a los calendarios se dio a través de la obra las Etimologías de Isidoro de Sevilla ${ }^{20}$, en la que el hispalense ofrece sus particulares interpretaciones etimológicas a los nombres de los meses. Para el mes de enero nos dice: "recibe su nombre del dios Jano, a quien lo consagraron los gentiles; o tal vez porque este mes es el umbral y la puerta (lanua) del año" (V,33,3-12). Para esta interpretación, Isidoro debió inspirarse en los Fastos de Ovidio donde se describe para enero: "Dios Jano

18. Castiñeiras, M. A., El calendario medieval... p. 121.

19. Capelli, A., Cronologia, Cronografia e Calendario Perpetuo, dal principio dell'era cristiana ai nostri giorni. Editore Ulrico Hoepli Milano, pp. 24-31.

20. Esta tesis la desarrolla con mayor extensión Castiñeiras en: "Las fuentes antiguas en el menologio medieval hispano: la pervivencia literaria e iconográfica de la Etimologías de Isidoro y el calendario de Filócalo". Boletín del Museo Arqueológico Nacional, XII, 1994, pp. 77-100. 
bicéfalo" (Fast,l,64). "Todo lo abre y cierra mi mano "(Fast I, 118). "Guardo las puertas del cielo ( ) de ahí que me llamen Jano (ianua-puerta)" (I, 125-128).

Dentro de la tradición literaria hispana contamos con textos en los que aparecen descritos los meses del año. Tal es el caso del Libro de Alixandre ${ }^{21}$ (ca. 1200-1231) en el que encontramos una descripción a modo de ékfrasis de la tienda imperial de Alejandro entre cuyos elementos se halla una parte decorada con un calendario ${ }^{22}$. Leemos en el mes de enero:

"Estava don Janero a dos partes cantando"

Son numerosas las representaciones del busto doble de Jano en monedas antiguas, pero son más escasas en las que aparece como figura de cuerpo entero. Su efigie asociada a los ciclos mensuales no surge hasta la época carolingia. Una aguda observación de Castiñeiras, nos hace ver que el Jano treviñés corresponde a la tipología de "in templo suo", pues parece estar bajo la bóveda de cañón de su templo mientras abre las puertas con sus manos. Responde la figura a un esquema escultórico antiquizante, heredera del modelo primitivo del panteón de San Isidoro de León (1072-1101), pero mucho más cercana al Jano de Mimizan (Principios del XIII) ${ }^{23}$. A su vez encuentra paralelismos con el Jano de la portada norte de la fachada occidental de Chartres (1220-1230 ${ }^{24}$ que se muestra sentado y bajo una arcada, probablemente un residuo de la copia de los modelos manuscritos en los que las efigies a menudo aparecen cobijadas bajo estas construcciones (Ms. Theol. Lat. 192, Berlin, Staatsbibliothek o el Matirologio de Wandalbert).

En el modelo chartriano queda visualmente definido el significado de esta imagen, mostrando un Jano bicéfalo con un rostro joven (el año que viene) y otro

21. Gonzalo de Berceo, El Libro de Alixandre, (ed. Dana Arthur Nelson), Biblioteca Románica Hispánica (Gredos), Madrid, 1978. También contamos con el texto del Arcipreste de Hita en su Libro del Buen Amor donde se describe de nuevo una tienda con los meses agrupados de cuatro en cuatro. Por su cronología tardía (1333-1340) y por tratarse de una obra en su mayor parte inspirada en el Libro de Alixandre, no la tendremos en cuenta para nuestro estudio.

22. "En un de los fastiales luego en la entrada

la natura del año sedié toda pintada;

los meses con sus días, con su luna contada,

ca [sc] uno quál fazienda avié acomendada."

23. Castiñeiras, M. A., El calendario medieval... p.125.

24. Para realizar el contraste con los repertorios franceses e italianos seguiremos especialmente la obra de Perrine Mane, Calendriers et Techniques Agricoles (France-Italie, XII-XIII siècles), Le sycomore, Paris 1983, y la citada obra de Webster. También una obra de consulta obligada para este tema es la nueva edición temática del Index of Christian Art, donde se recoge un nutrido repertorio de imágenes, si bien los textos ofrecen poco interés en tanto que no pasan de una mera introducción. Hourihane, Colum (ed.), Time in the Medieval World, occupations of the months \& signs of the zodiac in the Index of Christian Art, Pennsylvania State University Press, Princeton, 2007. 
anciano (el año que se va). Desgraciadamente el paso del tiempo ha hecho que el ejemplo treviñés nos haya llegado descabezado, lo que nos impide precisar mejor sus precedentes. Guarda también estrecha semejanza con la clave del claustro de la catedral de Pamplona en el tratamiento de la toga, fiel continuadora de la tradición antiquizante, pero responde a la tipología de Jano Claviger por las dos grandes llaves que porta.

\section{Febrero-Anciano al fuego:}

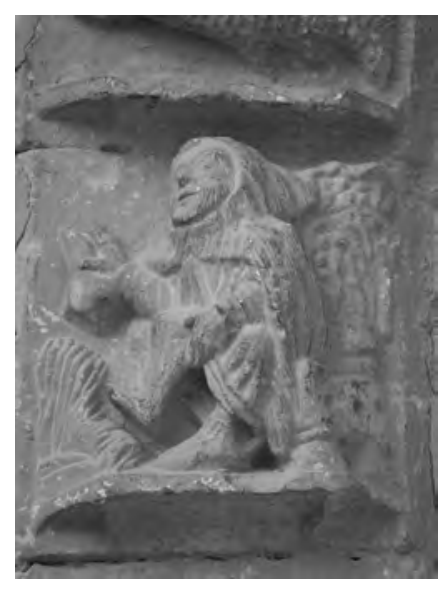

Figura 4: Detalle Febrero.

Para la figura de febrero observamos al tradicional personaje junto al fuego (Fig. 4). Para trazar su recorrido iconográfico debemos remontarnos a los ciclos mensuales de la antigüedad. En el tetrástico que acompaña el Enero del calendario de Filócalo ${ }^{25}$, se cita a Jano como dios titular del mes, se describen los actos dedicados a los lares donde se colocaba incienso ardiendo en los altares, y se señala que es en el comienzo del año cuando se realizan los actos oficiales en los que los cónsules son presentados con una copia de los fastos forrada en púrpura. En la ilustración que acompaña al texto aparece un hombre realizando el ritual dedicado a los lares en los que se quemaba incienso en su honor. Éste calendario cuando llegó al imperio carolingio debió copiarse su tipo iconográfico desligado del contenido original, dando lugar al manuscrito Ms. 387 de Viena en el que vemos a un personaje agachado calentándose al fuego. Este último se consolida así como el referente de todos los "ancianos al fuego" posteriores que evolucionaran adoptando todo tipo de actitudes.

La vejez del personaje treviñés se explica porque en la Roma prejuliana febrero era el último mes del año. La imagen del hombre viejo no es otra cosa que la personificación del año declinante, el año que toca a su fin. Ésta tradición tuvo su reflejo más importante en los calendarios bizantinos, cuya culminación paradigmática la vemos en el menologio de San Marcos de Venecia, y a través de éstos penetró en el mundo accidental ${ }^{26}$. Una posible repercusión de

25. Hic lani mensis sacer est; en aspice ut aris

tura micent, sumant ut pia tura Lares.

Annorum saeclique caput, natalis honorum,

purpureis fastis qui numerat proceres.

26. Stern, Henri, Le calendrier de 354, Étude sur son texte et ses illustrations, Institut Français D’Archeologique et Historique, Tome LV, Paris, 1953, p. 231. 
esta corriente la podemos ver en el libro de Alixandre pues no olvidemos que sus descripciones de los meses son de carácter itálico-bizantino. Leemos en relación a este mes:

"Estava don Febrero sus manos calentando,"

En los siglos del gótico el tema fue desarrollado a la vez que dotado de mayor naturalismo. En el caso del febrero de Treviño el anciano no sólo se calienta al fuego, también vemos cómo se quita la bota para calentarse directamente los pies. Estos modelos entraron a finales del XII a la península ibérica provenientes de Inglaterra ${ }^{27}$ donde apreciamos elementos anecdóticos de interior. Pero el ejemplo que nos ocupa está más relacionado con la tradición francesa de las pinturas de Pritz (principios del XII), el febrero de Santa Magdalena de Vezelay (1120-1132), el ejemplar del basamento de la puerta central de la fachada occidental de Senlis (1170), la puerta norte de la fachada occidental de la catedral de Notre Dame de París (1220) y, más estrechamente, con el febrero del ciclo monumental de la fachada occidental de Rampillon (1240-1250). Es también de reseñar la enorme semejanza con el febrero de un manuscrito francés del siglo XIII conservado hoy en Nueva York ${ }^{28}$. Pero es el ejemplo del claustro pamplonés el que guarda una dependencia casi absoluta pues la figura comparte la peculiaridad de sostenerse con una mano la pierna que acerca al fuego. Este gesto aparece en el enero de la portada central de la fachada occidental de San Marcos de Venecia (1240-1275) ${ }^{29}$, ciclo con el que parece relacionarse la arquivolta de Treviño y al que volveremos en otros ejemplos.

\section{Marzo-poda de la vid:}

Antes de comenzar el comentario, cabe precisar que la figura que sigue a continuación de febrero es mayo y no marzo (Fig. 5). Este error pudo deberse a la explicación que anteriormente planteábamos con respecto al posible desconocimiento de la iconografía representada por parte de los canteros encargados de montar las dovelas esculpidas en el taller. En cualquier caso, para no romper el sentido cronológico de la serie analizaremos esta figura en su lugar preciso.

27. Castiñeiras, M. A., El calendario medieval... p.150.

28. New York, Pierpont Morgan Library, Ms. M.92, fol. 15v, Hours, Francia, segundo cuarto del XIII.

29. Este gesto peculiar pudo nacer en Italia como contaminación iconográfica con el espinario. En este país, marzo habitualmente se representaba con el joven que se sostiene un pie para sacarse la espina de la planta (podemos ver un ejemplo en uno de los canecillos de Armentia). La confusión parece gestarse en el marzo-espinario del baptisterio de Pisa (segunda mitad del XII) donde vemos un personaje togado sentado en un taburete sacándose la espina, pero esta vez visto de lateral y no de modo frontal como solía representarse. A esta figura sólo faltaba añadirle el fuego para convertirse en el enero de San Marcos de Venecia, donde vemos ya un anciano al fuego sosteniéndose el pie, sentado sobre un taburete. 


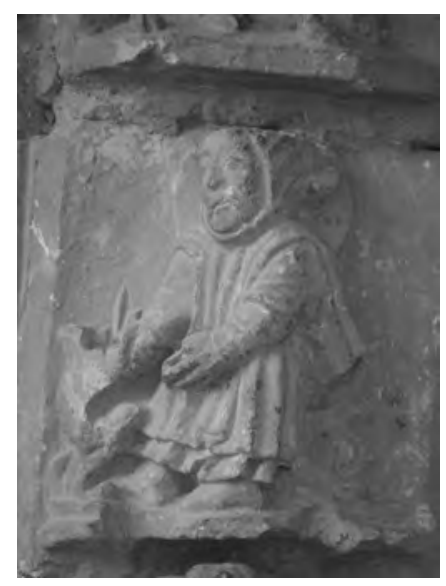

Figura 5: Detalle Marzo.

Tal y como nos dice Paladio (s $\vee$ d.C.), el tratadista de agricultura más difundido en época medieval ${ }^{30}$, "en este mes, en sitios fríos se realizará la poda de las cepas" (Tratado de Agricultura, IV,I). Sin embargo también señala que en mayo deben hacerse varias labores relacionadas con las vides como la colocación de rodrigones, examinar los nuevos sarmientos, despampanar para que penetre mejor el sol o el acollamiento de las cepas (TA, VI, I-IV), por lo que bien pudieron confundir los canteros el orden de las dovelas atendiendo más a su propia vida rural que a la tradición iconográfica.

La figura corresponde al tradicional modelo de poda que vemos en los menologios del Panteón Real de San Isidoro de León, la fachada occidental de Vezelay (1120-1132), Senlis, Rampillón, la vidriera del deambulatorio de Chartres (1217-1218) y de nuevo en la clave del claustro navarro. Destacamos por encima de todas la semejanza con el febrero de la fachada norte de Chartres (1220-1230) cuya vestimenta y postura es prácticamente exacta. El podador treviñés tiene la peculiaridad de poseer una esfera tras su cabeza, como si se tratara de un nimbo, que probablemente aluda al sol que comienza a aparecer una vez pasados los fríos invernales. Este mismo motivo lo veremos en el personaje de abril.

La iconografía de la poda se gesta también en época carolingia, teniendo uno de los primeros modelos en el sacramentario de Berlín del siglo $X^{31}$. En estos tiempos de esplendor carolingio tuvo una especial presencia el tratado de Paladio como referente teórico para el trabajo de la tierra. En palabras de Moure Casas, "el renacimiento carolingio y la hegemonía cultural del área francesa constituyen ahora el marco histórico y geográfico de la difusión de la obra de Paladio" ${ }^{132}$. Para la creación del tipo iconográfico sólo necesitaban copiar los modelos de la siega de la mies, tan habituales y difundidos en el mundo clásico como alegorías estacionales a través de sepulcros y mosaicos, y adaptarlo al tema de la poda.

Leemos en el Libro de Alixandre una descripción que se ajusta en gran medida a la imagen:

30. Paladio, Tratado de Agricultura, "introducción" por Ana Moure Casas. Bilioteca clásica Gredos, 135. Madrid, 1990.

31. Castiñeiras, M. A., El calendario medieval... p. 195.

32. En Paladio, "Introducción", Tratado de... p. 49. 
"Março avié grant priessa de sus viñas labrar, priessa con podadores e priessa de cavar;"

\section{Abril-príncipe de la primavera:}

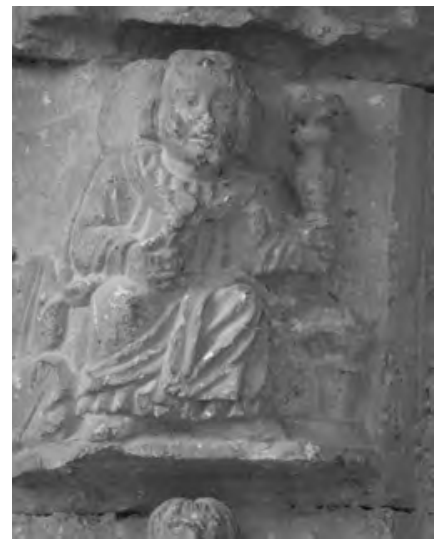

Figura 6: Detalle abril.

Para este mes, la correspondiente arquivolta nos muestra un joven imberbe entronizado y vestido con ricas ropas (Fig. 6). En su mano izquierda porta un ramo de flores y en la derecha una especie de cetro. A su lado se esculpe lo que parece un jarrón con flores. Se nos muestra joven, pues abril es el mes en el que renace la vida tras el invierno. Esta figura se asocia al rey de primavera cuyos modelos más cercanos parecen atender a influencias italianas y francesas. En el claustro de Tarragona vemos un personaje entronizado recibiendo un objeto de otro genuflexo mientras sostiene en su mano derecha un ramo de flores ${ }^{33}$. Pero los paralelismos italianos más próximos al tipo iconográfico, derivan del mayo de San Marcos de Venecia donde una figura entronizada está siendo coronada por dos doncellas.

Emile Mâle señala que el modelo de rey de primavera ${ }^{34}$ en Francia sigue el esquema del salterio del siglo XII B.N., ms. Latino 238, "donde nos muestra a abril bajo la figura de un rey majestuosamente sentado, con una rama tierna en una mano y el cetro en la otra"35. En el país galo encontramos ejemplos que se acercan a nuestro abril en Rampillón, en el basamento de la puerta norte de la fachada occidental de Amiens (1225-1235) y en un Breviario de finales de XIII' ${ }^{36}$. En esta misma línea apunta la descripción del Libro de Alixandre, esta vez para el mes de mayo:

"Sedié el mes de Mayo coronado de flores,"

Así pues de nuevo vemos una influencia italiana palpable, quizá proveniente de modelos bizantinos que a su vez pasaron a Francia, dando lugar a un tipo

33. Esta representación según J. Puig I Cadafalch y Webster (Cfr. Castiñeiras, M. A., El calendario medieval... p. 135) parece mostrarnos una trasposición de una ceremonia feudal, en la que se realiza la entrega de un objeto simbólico para la investidura del rey.

34. O tal vez sea el príncipe de la juventud que nombraban los jóvenes de Soissons a finales de la Edad Media. Mâle, Emile, El Gótico, La iconografía de la Edad Media y sus fuentes, Ediciones Encuentro, Madrid, 1986, p. 107, nota 31.

35. Mâle, E., El gótico p. 88.

36. New York, Pierpont Morgan Library, Ms. M.1042, fol. 3r, Breviary, Francia, 1285-1297. 
iconográfico más o menos común en ambos países y que tendría su reflejo hispano en los ejemplos mencionados.

\section{Mayo-Halconero:}

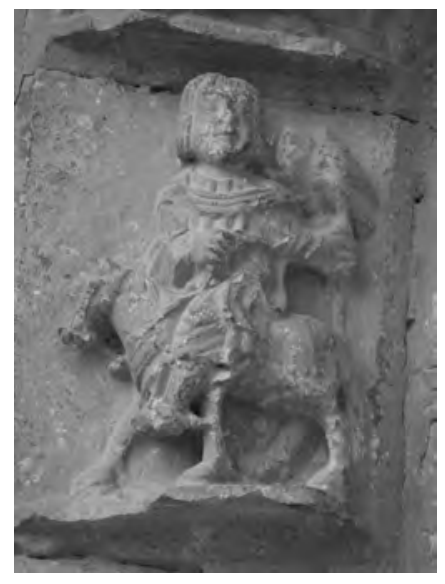

Figura 7: Detalle mayo.

El mayo de Treviño se ilustra con el característico halconero a caballo ${ }^{37}$ (Fig 7), tema asociado a la nobleza en relación directa con el rey de primavera. La cetrería y la caza en general fueron las actividades preferidas de las clases altas. Mediante ellas se ejercitaban físicamente para la guerra y además mostraban de manera fehaciente su diferencia con respecto a los trabajadores de la tierra. En ocasiones, cuando el caballero porta un ramo de flores, representa el paseo primaveral del caballero, muy en relación con el amor cortés que comenzó a extenderse a lo largo del S. XII desde la Provenza hasta el resto de Europa ${ }^{38}$.

En la provincia de Álava contamos con un mayo-halconero en la basílica de Armentia situado en el capitel del interior de la ventana absidial del lado del Evangelio (S. XII) y de similares características al ejemplar treviñés. Ruiz Maldonado señala que se trata de un jinete llevando las riendas de su montura en

37. El motivo del personaje a caballo para el mes de mayo, viene desde la reforma de Pipino el Breve (S. VIII), que instauró el Campus Madii (antes Campus Martius) pues los pastos eran mejores para los caballos y así emprenderían mejor las batallas (Castiñeiras, M. A. "Algunos testimonios hispanos del "Campus Madii": el mayo guerrero de San Isidoro de León", III Coloquio de Iconografía. Madrid 1992. Actas Cuadernos de Arte e Iconografía, VI, 1993, pp.75-79). Este cambio bien pudo deberse a la experiencia personal del militar, pero sería igualmente plausible pensar que tuvo que basarse en textos que avalaran con autoridad su decisión. Analizando los tratados de agricultura de COLUMELA (Res Rustica) (S. I d.C.) y Paladio (Opus Agriculturae) (S IV-V d.C.), encontramos bien argumentados los motivos que pudieron motivar a Pipino a adoptar la reforma. Paladio nos señala que "durante este mes en lugares secos y calurosos, o bien marítimos, se siega el heno, antes de que se agoste $(\mathrm{VI}, 1)^{\prime \prime}$. Es importante el detalle de "antes de que se agoste" pues encontramos en Columela el porqué de esta preocupación y con ello la clave para entender el cambio de Pipino el breve. El gaditano en su pseudo-almanaque, nos dice que "por estos días (...) han de empezarse a segar los henos" (XI,2,), pero en su libro II (II, 18, 1-3), nos lo argumenta con gran profusión: "Lo mejor es segar el heno antes de que se seque, pues cunde más y las bestias lo comen con más gusto, pero debe buscarse el punto justo de sequedad y no recogerlo ni demasiado seco ni, al contrario, todavía verde; lo uno porque si ha perdido todo su jugo, viene a ser lo mismo que la paja, y lo otro porque si ha conservado demasiada humedad, se pudre (...)".

38. Porter, Pamela, El amor cortés en los manuscritos medievales, Ay N ediciones, Madrid, 2006, p. 33. 
su mano derecha y un azor en la izquierda ${ }^{39}$, pero esta escultura parece seguir fielmente al halconero de Beleña de Sorbe, por lo que habría que considerarlo como un ejemplo aislado tomado de un repertorio mensual. Castiñeiras apunta que los modelos de halconero a caballo debieron entrar tardíamente en la península directamente de Inglaterra ${ }^{40}$, pues Francia e Italia siguen un esquema diferente. Sin embargo, el noble a caballo practicando la cetrería independiente de los ciclos calendáricos lo vemos en obras de pintura (pinturas mozárabes de San Baudelio de Berlanga, principios del $\mathrm{XII}^{41}$ ) o esculturas (arqueta de Leyre o decoración monumental de Santa María del Naranco), por lo que los artistas ya debían conocer estas figuras al realizar los primeros menologios.

Por tanto, señalar precedentes iconográficos para el halconero a caballo de Treviño resultaría tarea demasiado difusa, ya que es un modelo que se difundió enormemente ${ }^{42}$. Como referencia, anotar que guarda similitudes con el mayo del claustro pamplonés, aunque el naturalismo de éste denota una mano mucho más avanzada y además estaría aludiendo también al paseo primaveral.

\section{Agosto-Trilla:}

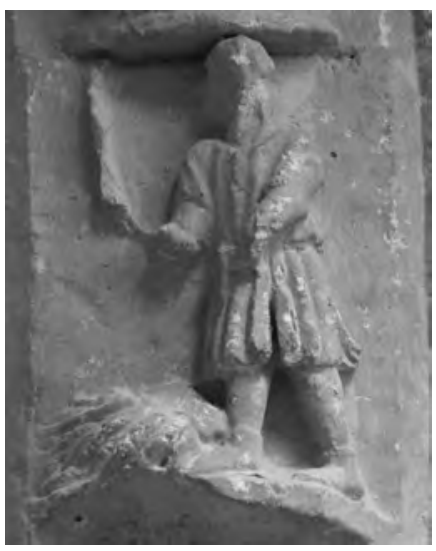

Figura 8: Detalle agosto.
Tras unas dovelas, cuya interpretación abordaremos posteriormente, continúa el repertorio con el mes de Agosto (Fig. 8). Para su representación se recurre a la escena del campesino golpeando con el mayal la mies tendida en la era. En la península esta iconografía arranca en el agosto del Panteón Real de San Isidoro y será el modelo que triunfe con muy pocas variaciones. En Francia se extiende esta misma representación y de nuevo sus únicas diferencias se observan al añadir elementos anecdóticos a la escena. Podrían enumerarse gran cantidad de precedentes para la composición de Treviño ${ }^{43}$, pero es en Amiens donde encontramos mayores similitudes ya que ambos, además de situarse en

39. Ruiz Maldonado, M., Escultura románica alavesa: El foco de Armentia, Servicio Editorial de la Universidad del Pais Vasco, Bilbao, 1991, p. 39.

40. Castiñeiras, M. A., El calendario medieval... p.162.

41. En esta obra mozárabe, vemos varias escenas cinegéticas entre las que se observa un halconero, un cazador a caballo corriendo liebres, o un cazador hiriendo a un ciervo, Camón Aznar, José, "Pinturas mozárabes de San Baudelio de Berlanga", Goya, Madrid, 1958, pp. 76-80.

42. Ver el repertorio ofrecido por Hourihane, C., Time in Medieval Wold..., pp. 113-125.

43. Pinturas murales de Pritz, vidirera de Chartres, Rampillón, Vezelay, así como otros ejemplos hispanos en Betanzos, Nieva, El Frago, Navasa o Campisábalos. 
una postura calcada, visten túnica corta propia de los meses calurosos. Por su parte el Libro de Alixandre nos recuerda para este mes:

"Trillaba don Agosto las miesses por las eras"

\section{Septiembre-vendimia:}

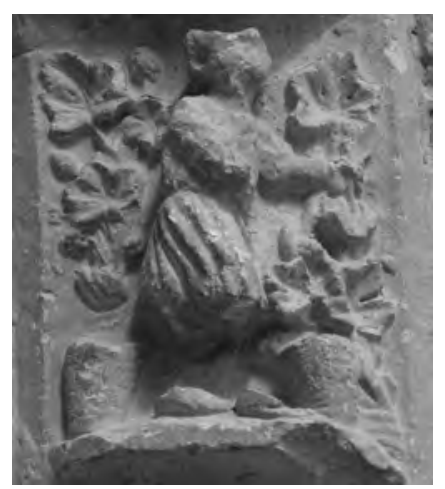

Figura 9: Detalle

Septiembre.

El mes de septiembre se representa con la vendimia de la uva (Fig. 9). Paladio nos dice que "durante este mes, en los lugares templados y marítimos debe realizarse la vendimia" (X, 12). Prácticamente todos los menologios recogen esta escena ya que junto con la siega era uno de los pilares de las labores agrícolas ${ }^{44}$. Los buenos cuidados realizados en los meses anteriores (poda de marzo) ahora debían dar sus frutos para asegurar así un invierno bien suministrado. La dovela treviñesa sigue el modelo establecido para septiembre en el Panteón Real, pero incorpora un mayor desarrollo de los pámpanos en línea con el naturalismo gótico. Al igual que el ejemplar de Beleña de Sorbe, con una mano agarra la vid mientras que con la otra corta el racimo dejándolo caer en un cesto dispuesto en el suelo ${ }^{45}$. El trabajo escultórico de los pámpanos es el mismo que el realizado para la escena de vendimia de la peana de la Virgen Blanca anteriormente mencionada.

Parece acertado vincular esta dovela con los modelos hispanos, pues aunque observamos numerosas obras similares ${ }^{46}$, se encuentra más cercana a las piezas peninsulares. De nuevo el Libro de Alixandre alude a esta escena:

"vendimiava las viñas con falces podaderas"

44. Desde la Antigüedad estas dos faenas se representaron con gran profusión especialmente en los sarcófagos y mosaicos dedicados a las estaciones. Uno de los ejemplos más sobresalientes es el sarcófago de Juno Basso en cuyos laterales se despliegan unas escenas relativas a las estaciones del año entre las que la siega y la vendimia tienen un significativo desarrollo.

45. Castiñeiras vincula además con este modelo iconográfico los ejemplares de Perazancas, El Frago, Hormaza, Beleña y Roda. Castiñeiras, M. A., El calendario medieval... p.205.

46. En Italia San Giorgo de Ferrara, museo del duomo (S XIII), mosaico pavimental de S. Michele de Pavía (1100) o en la portada central de la fachada occidental de Santa Maria della Pieve en Arezzo (1220); en Francia, en cambio es más frecuente la escena del pisado de uva o transporte de la misma, aunque aparece algún ejemplo como el de Vezelay. 


\section{Octubre-trasiego:}

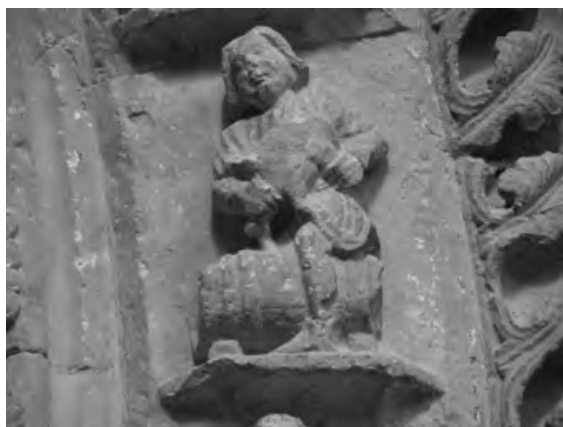

Figura 10: Detalle Octubre.

En estrecha relación con la escena anterior, aparece representado el proceso de trasiego del vino del odre a la barrica de madera (Fig. 10). Ofrece la peculiaridad de mostrar al personaje subido a horcajadas sobre la cuba, característica que entra en la península por la influencia de las obras góticas de la Isla de Francia. Este modelo aparece en Saint-Dennis tanto en el ciclo monumental de la puerta sur de la fachada occidental (1130), como en el menologio musivario que se despliega en el pavimento de la capilla de SaintFirmin (1200). Es en este último en el que se inspiraría la obra de Treviño pues a pesar de existir multitud de ejemplos de trasiego tanto en España como en Francia o Italia, el detalle de la figura subida a horcajadas hace que tengamos que mirar al citado mosaico de Saint-Dennis para establecer la relación más acertada.

Paladio en su Tratado de Agricultura, dedica uno de sus apartados más extensos a la preparación del vino una vez hecha la vendimia (XI, 14), citando entre otras muchas actividades el trasiego.

\section{Noviembre-matanza:}

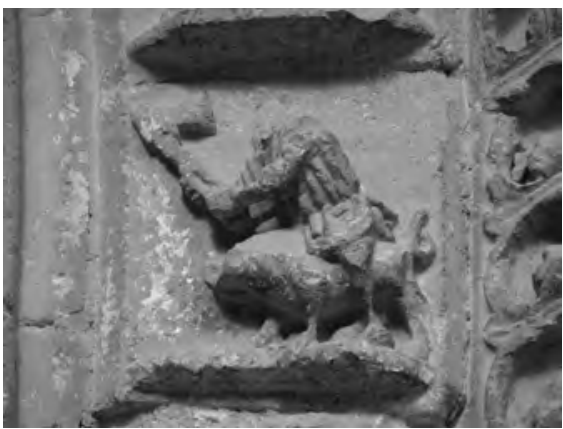

Figura 11: Detalle Noviembre.
Para la representación de noviembre se recurre al tema doméstico de la matanza del cerdo (Fig. 11). Existen muchas variantes de este tema, desde la apertura en canal del animal hasta el momento justo de asestarle el golpe mortal. En Treviño se sigue este motivo y de nuevo se incorporan las novedades góticas pues el personaje aparece subido a horcajadas sobre el porcino. Como nos explica Castiñeiras, esta escena aparece en los ciclos hispanos en noviembre ya que existía en el mundo medieval una fuerte tradición de celebrar la matanza el día de San Martín (11 de noviembre) y así se dejaba la escena del banquete para diciembre ${ }^{47}$.

47. Castiñeiras, M. A., El calendario medieval... p. 221. 
En las cercanías de Treviño encontramos otras escenas de matanza de cerdo, pero esta vez siguen esquemas diferenciados y no guardan relación alguna con la dovela de noviembre. Una muestra sobresaliente, que además nos pone de manifiesto la circulación de modelos catalanes por estas tierras, es la matanza que se desarrolla en un capitel de la portada del baptisterio de Uzquiano (procedente de Ochate), dependiente en todos los detalles con respecto al noviembre del menologio de Ripoll. Sin embargo la obra treviñesa sigue las directrices establecidas con el matarife a horcajadas de la fachada occidental de Chartres, obra que tendrá su correspondencia también en el calendario de Nieva.

\section{Diciembre-festín:}

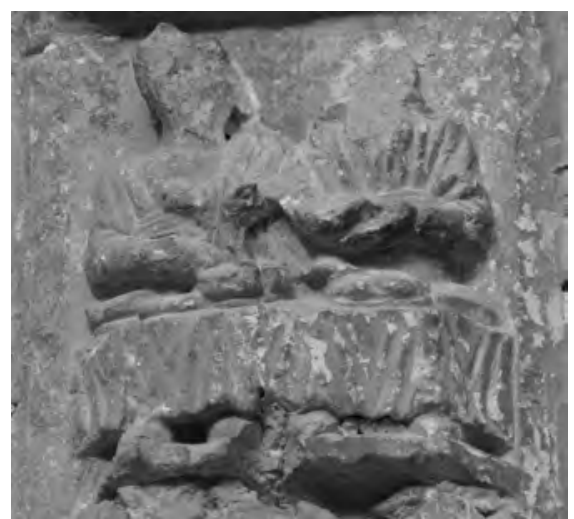

Figura 12: Detalle Diciembre.

En esta última dovela, dos comensales se disponen a celebrar con un gran festín el final de los trabajos del campo (Fig. 12). Una vez realizada la siega, vendimiada la vid y matado el cerdo, un buen banquete culmina todo un año de duros trabajos. Lamentablemente, al igual que ocurre con algunas dovelas anteriores, el paso del tiempo ha hecho que nos hayan Ilegado deterioradas y nos impide precisar qué portarían en las manos ambos personajes, quizá estén compartiendo un cuenco con el vino obtenido apenas dos meses antes.

El modelo de dos personajes comiendo a la mesa deriva directamente del diciembre de la fachada occidental de Chartres. Esta escena de diciembre puede ofrecer grandes variaciones en función del número de comensales a la mesa, los detalles que adornan la composición e incluso a veces aparecen contaminadas las iconografías colocando a Jano ante el banquete. Sin embargo el modelo chartriano muestra a dos personajes comiendo en una mesa sencilla y compartiendo un recipiente al igual que en el ejemplar de Treviño.

\subsubsection{Dovelas "No identificadas"}

Como se ha señalado, en la parte superior de la portada hay cinco dovelas cuya identificación es muy problemática. Su iconografía aparentemente no sigue ninguno de los modelos de las representaciones mensuales citadas, por lo que debemos buscar en otro tipo de obras más ricas por su mayor sentido narrativo. 


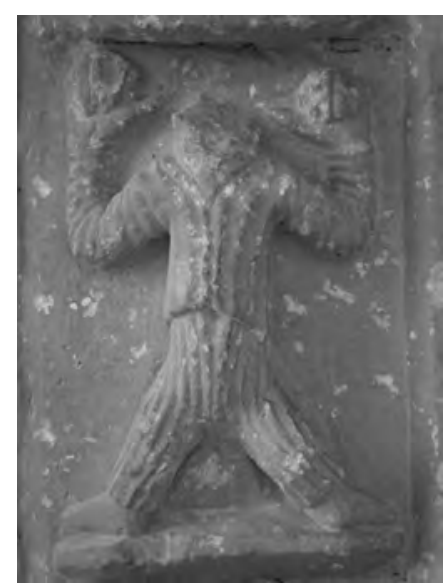

Figura 13: Detalle "cornero".

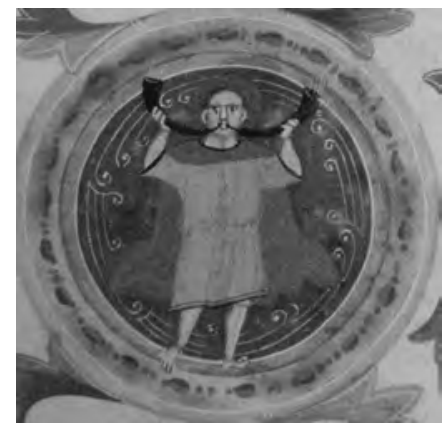

Figura 14: P.M.L., Ms. M.511, fol. 2r, detalle marzo (Hourihane).

Es el caso de la dovela que sigue a la del signo zodiacal de Leo. En ella se muestra una figura de gran tamaño (Fig. 13) dispuesta de forma frontal con los brazos levantados a la altura de la cabeza. Ruiz Maldonado se muestra cauta en sus observaciones y comenta que la mano derecha del personaje podría estar sujetando un objeto, hoy destruido, relacionado con alguna de las faenas propias del mes de junio o julio ${ }^{48}$. Frontón Simón señala que pudiera tratarse del profeta Daniel, asociado al león (Leo) y en relación a ello plantea una sugerente teoría vinculando esta imagen a los zodíacos moralizados del XIV. Es conocida la polémica antiastrológica, nacida a partir del XI y XII, y su posterior resurgimiento entre los siglos XII y XIV, como resultado de la traducción de obras astrológicas en Toledo ${ }^{49}$. Por tanto, si considerásemos esta imagen como la de Daniel y las tres dovelas más pequeñas como una Anunciación, podríamos entresacar soluciones a este rompecabezas de tipo teológico atendiendo a los numerosos autores cristianos que buscaron otorgar un significado moralizado al zodíaco. Pero incurriríamos en un grave error si sólo observáramos en ellas su iconografía dejando de lado los aspectos estilísticos. Es tentador apuntar que las dovelas "sin identificar" fueron incluidas con una finalidad "cristianizadora" para que el conjunto de la portada no resultara demasiado profana, pero salta a la vista una diferencia de estilo más que notoria entre ambas figuras, por lo que debemos rechazar que se cincelaran al mismo tiempo atendiendo a una motivación común.

48. Ruiz Maldonado, M., "Precisiones...", p. 9.

49. Frontón Simón, I., “El calendario medieval..." p. 176. 


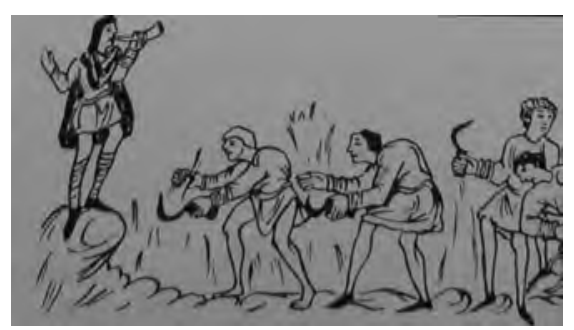

Figura 15: Ms. Cott. Tib. B. V, Detalle junio (Webster).

Castiñeiras sugiere con sensatez que el mencionado "monigote" pudiera ser un espantapájaros ${ }^{50}$ o quizá algún personaje de la cultura popular como el chachimorro que alegraba las festividades de San Juan en las Vancongadas ${ }^{51}$.

Por todo ello, trataremos de ofrecer para esta dovela unas teorías, inevitablemente especulativas por la carencia absoluta de pistas o atributos, sin salirnos de la iconografía propia de los ciclos mensuales. En el análisis realizado para las figuras anteriores hemos podido ver una relación más o menos directa con los ciclos italianos. Es en este país donde se gestó una iconografía local para alguno de los meses (pesca-febrero o marzoespinario), cuya repercusión prácticamente pasó desapercibida en el resto de Europa, pero que sin duda debió circular junto con el resto de imágenes.

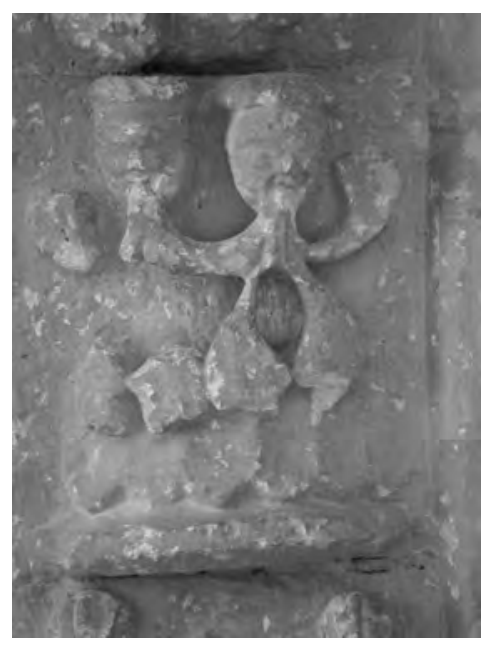

Figura 16: Detalle geminis.

Para la imagen de marzo, los ciclos italianos ofrecen una singular solución representando una alegoría de los vientos de corte clásico conocida como cornero. Podemos verla en las obras de San Zenon de Verona, San Sabino de Piacenza, San Michele de Pavia y otros tantos ejemplos en los que se mantiene el mismo tipo iconográfico. Se trata de una figura dispuesta de forma estrictamente frontal, con los brazos elevados a la altura de la boca, mientras sujeta con sus manos dos grandes cuernos u olifantes que hace soplar, quedando el gesto recogido mediante el agitado alboroto de sus cabellos. Tomamos como ejemplo el marzo de un manuscrito italiano conservado en Nueva York ${ }^{52}$ (Fig. 14). Una iconografía muy similar pero esta vez en busto se esculpe en las claves del citado claustro de la catedral de Pamplona para las

50. Es sin duda ingeniosa la relación con un espantapájaros, y de hecho la figura parece tener los pies hacia dentro, como si estuvieran las piernas al revés, signo de deshumanización. Sin embargo el arte apenas ofrece ejemplos que nos den pistas, tan sólo en el octubre de las miniaturas del libro de horas del Duque de Berry nos muestra un espantapájaros ataviado con un arco mientras los agricultores siembran el cereal.

51. Castiñeiras, M. A., El calendario medieval... p. 106.

52. New York, Pierpont Morgan Library, Ms. M.511, fol. 2r, Calendario, Italia, c. 1324-1328. 
imágenes de los cuatro vientos. Con todo, aunque las similitudes entre el marzo italiano y la dovela treviñesa son patentes, el mes de marzo había quedado ya reflejado con la poda.

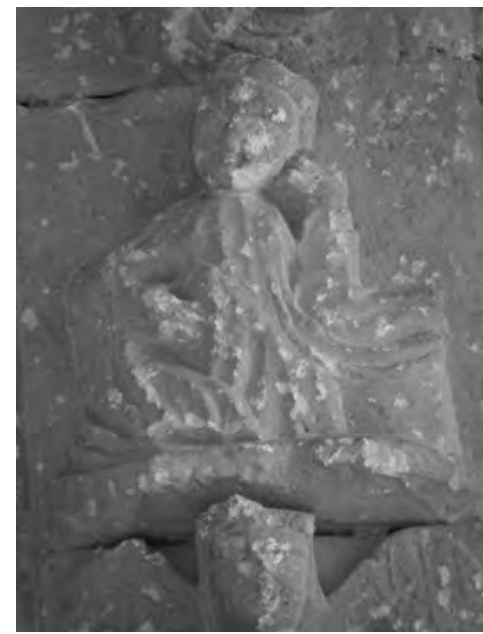

Figura 17: Detalle "Anunciación".

Sin salirnos del tema del cornero, son muy habituales las escenas en las que este personaje acompaña las cacerías y las guía con su olifante, pero éstas se dan en época invernal y las dovelas para esta estación están también cubiertas. Sin embargo, dos manuscritos ingleses del siglo XI, pertenecientes a la escuela de Winchester $y$ hoy conservados en el British Museum, nos muestran unas claves que sugieren nuevas hipótesis ${ }^{53}$.

En el registro de junio del manuscrito Ms. Cott. Tib. B.V (Fig. 15), se ilustra el proceso de siega de la mies con la cosecha, el enfardado, traslado de gavillas y la trilla. Pero nos detendremos en un personaje que aparece a la izquierda ricamente ataviado, en postura frontal y con un cuerno en su mano izquierda. Webster no señala nada sobre esta figura que, probablemente, ilustraría al señor de las tierras con su cuerno anunciando el inicio de los trabajos. El esquema compositivo es muy similar al de la figura treviñesa, pero la vestimenta lo diferencia notablemente. Por tanto no podemos asegurar que sea ésta la clave que explique el significado de dicha dovela, pero sí podemos sugerir que en Treviño se quisiera acaso representar con el cornero el mes de junio y para julio se reservaría la clásica imagen de siega de la mies que aparece en la práctica totalidad de los menologios medievales ${ }^{54}$.

En la portada de Peñacerrada, que además ofrece ciertos rasgos de dependencia y se encuentra a pocos kilómetros, aparece un cornero bien identificable con su olifante, lo que nos demuestra que tal iconografía era conocida por los artistas de la zona.

53. Se trata por una parte del manuscrito Cottonianus Julius A.VI, donde los meses son ilustrados con registros de gran desarrollo narrativo incluyendo para cada uno de ellos varias figuras; y por otra, el manuscrito Cottonianus Tiberius B.V. que mantiene una iconografía prácticamente exacta con pequeñas variaciones. Cfr. Webster, J. C., The Labors of the Months... pp. 53-55.

54. Hoy esta dovela se encuentra desaparecida, o quizá nunca llegó a colocarse por algún motivo desconocido, pero a buen seguro el calendario de San Pedro de Treviño se ideó con esta figura ya que, como hemos visto, en agosto aparece la trilla. 


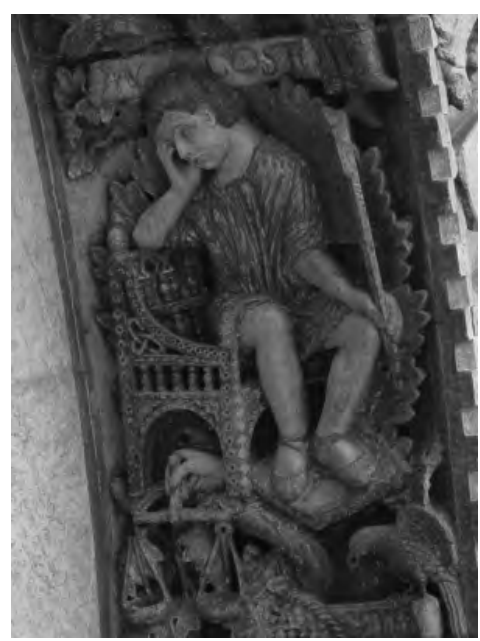

Figura 18: San Marcos de Venecia, detalle agosto.

Inmediatamente después de la dovela del "cornero", aparecen cuatro de menor tamaño y con una iconografía en principio ajena a la de los meses.

Comentaremos también la dovela que precede a la "Anunciación" y que se ha identificado por parte de los autores citados ${ }^{55}$ como géminis (representada por los dos los dos gemelos), ya que ofrece rasgos estilísticamente comunes y notoriamente diferenciados con las figuras "identificadas" (Fig. 16). Sin duda está esculpida por otro artista de carácter local. De nuevo podemos vincular esta imagen con la portada de Peñacerrada pues en ésta vemos una figura vomitando una suerte de tallos vegetales muy similares a los de la dovela de Treviño. Por tanto no podemos precisar con exactitud su identificación $y$, aunque resulte coherente relacionarla con los gemelos zodiacales, creemos que tal afirmación debe hacerse con ciertas reservas.

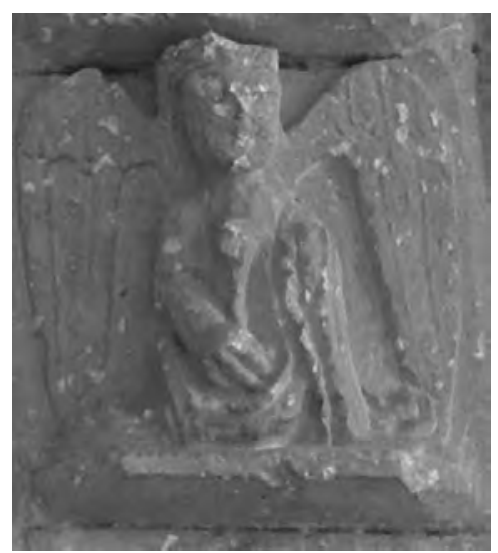

Figura 19: Detalle ángel.

De la mano del mismo artista salió la siguiente imagen $^{56}$ (Fig. 17), asimilada por quienes han estudiado la portada a la Virgen María que, junto con el ángel, se ha interpretado como una Anunciación. Se trata aparentemente de una efigie femenina sentada que porta un objeto en su mano derecha (tal vez un libro) y con la izquierda se apoya sobre un rectángulo indefinido para sostener su cabeza. Encontramos un paralelismo formal muy acusado en el agosto de San Marcos de Venecia (Fig. 18), donde vemos descansar a un joven campesino tras la dura faena de la siega. La fuente para esta imagen la encontramos en la obra De Hysmines et Hisminiae

55. Martinez de Salinas, F., "Portada de la parroquia..." p. 12; Ruiz Maldonado, M., "Precisiones..." p. 9; FRONTÓN SIMÓN, "El calendario medieval..." p. 172.

56. La cabeza de la figura y la forma de tallar el tocado, encuentra paralelismos exactos en ciertas figuras de la portada de Peñacerada. 
amoribus del filósofo griego Eustacio de Macrembolite (s. XII) quien nos dice que el mes de agosto se representa con un joven campesino cansado y sediento por la dura jornada de trabajo ${ }^{57}$.

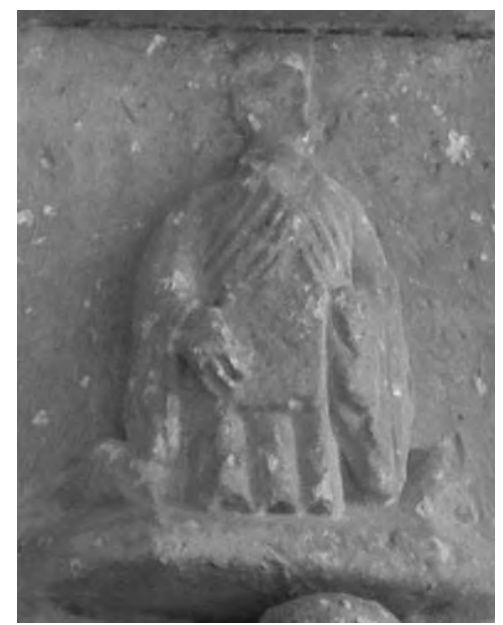

Figura 20: Detalle "profeta".

La siguiente dovela se decora con un ángel muy similar a los que ornamentan los arranques de las arquivoltas (Fig. 19). De nuevo podríamos ver en él a San Gabriel para completar así la escena de la salutación angélica, pero si continuamos sin desviarnos de la temática de la portada, bien podría tratarse de libra. El esquema formal estaría tomado de los ángeles mencionados, a lo que se le añadiría la báscula característica del signo zodiacal. Si observamos atentamente la imagen, el ángel sostiene con su mano derecha una vara vertical y, la izquierda, hoy perdida, parece situada como si estuviera agarrando el listón superior de una balanza.

Inmediatamente después aparece una dovela cuyo significado resulta enormemente difícil de descifrar por la carencia de atributos que la definan (Fig. 20). Vemos un personaje frontal con un objeto cuadrado sostenido por su tosca mano y con unos restos a ambos lados de algo que, si el tiempo no lo hubiera deteriorado, quizá hoy nos daría la pista que necesitamos. Siguiendo con el argumento de la Anunciación, se ha interpretado como un profeta, tal vez Henoc por ser, según la tradición judeocristiana, el inventor de la escritura y de la división del tiempo, y se ha sugerido una teoría en relación al por qué de la Anunciación ${ }^{58}$. Sin embargo parece contradictorio que la parte de la portada que ofrecería un mensaje de tipo teológico más elaborado y complejo se lleve a cabo con una factura formal y estilística notablemente inferior.

57. Stern, Henri, Le calendrier de 354, Étude sur son texte et ses illustrations, Institut Français D’Archeologique et Historique, Tome LV, Paris, 1953, p. 367.

58. "La Anunciación, introduce en el calendario astrológico de Treviño un matiz importante. Los hombres no están ya sujetos a los dictados de los signos ni bajo sus influjos o fatalismo. A través de María, en el momento de la Encarnación del Hijo, los cristianos tienen la promesa del libre albedrío, de la salvación y de la resurrección al final de los tiempos". Ruiz Maldonado, M., "Precisiones..." p. 10. 


\section{Conclusión}

Nos encontramos por tanto ante una portada probablemente levantada a finales del siglo XIII, con una iconografía muy variada que recoge las novedades surgidas en el prolífico gótico francés e italiano, pero que mantiene una cierta continuidad con la tradición de los menologios hispanos. La ejecución de algunas figuras nos hace pensar en la presencia de unos talleres escultóricos de relevancia (también por la diversidad de modelos empleados), por encima de la estética rural que se observa en la mayoría de las obras de los alrededores del condado. Sin embargo, hemos podido constatar la actuación de otras manos, sensiblemente menos dotadas, encargadas de culminar la obra en su totalidad.

Así pues, vistos los problemas existentes con estas dovelas, una posible solución sería la siguiente: la portada de Treviño, por algún motivo que desconocemos, no se completó de manera coherente con las dovelas "identificadas" en su parte superior. Para solucionarlo sería Ilamado un artista local (probablemente un escultor que trabajó en Peñacerrada), desconocedor de la temática mensual, que cerraría la portada con estas cuatro dovelas de menor calidad. Para su elaboración pudo valerse de los modelos del primer taller como el agosto de San Marcos de Venecia o los propios ángeles ya esculpidos de los arranques de las arquivoltas, para concluir de urgencia y, sin apenas recursos, la obra. Quizá en ocasiones debamos dejar un poco de lado las especulaciones teóricas para tratar de atender otras posibles causas más pragmáticas y terrenales.

Su tardía cronología con respecto al surgimiento de esta iconografía en el ámbito hispano y europeo, hace que la obra se encuentre muy influenciada por corrientes que apuntan a lugares diversos. Con respecto a Francia, las más destacadas dependencias provienen de la Isla de Francia, y más concretamente de Chartres, Saint Dennis y Amiens, sin olvidar por supuesto a Mimizan. En cuanto a Italia, se observa una relación estrecha con su corriente de corte bizantina analizada en San Marcos de Venecia. Resulta muy difícil desentrañar si estas influencias italianas llegaron directamente, o si por el contrario vinieron tamizadas por el país galo. En cualquier caso deviene interesantísimo observar cómo en una portada de población pequeña como es Treviño operan influencias directas de los más importantes talleres a nivel europeo.

Hecho pues el estudio iconográfico de los meses, quedaría ahora un estudio referente a los signos zodiacales para poder extraer del conjunto una conclusión final sobre su sentido iconológico. No cabe duda que las sugerencias aportadas en este trabajo no pasan de la mera hipótesis, pero la intención de este comentario no es sino presentar otros caminos diferentes, nuevas pistas que ayuden a resolver algún día este precioso rompecabezas en forma de portada. 